\title{
SELF ORGANIZING MAP OF ARTIFICIAL NEURAL NETWORK FOR DEFINING LEVEL OF SERVICE CRITERIA OF URBAN STREETS
}

\author{
Smruti Sourava Mohapatra', Prasanta Kumar Bhuyan ${ }^{2}$ \\ ${ }^{1,2}$ Department of Civil Engineering, National Institute of Technology, Rourkela, India 769008
}

Received 1 March 2012; accepted 27 July 2012

\begin{abstract}
In India, Level of Service (LOS) is not well defined for urban streets. The analysis procedure followed in India is that developed by HCM 2000. Speed ranges of LOS categories for various urban Street Classes defined by HCM are appropriate for developed countries having homogenous type of traffic flow. India being a developing country its traffic is very much heterogeneous having vehicles of different operational characteristics. Therefore, LOS criteria in Indian context should be defined correctly considering the traffic and geometric characteristics of urban streets. Defining LOS is basically a classification problem and application of cluster analysis is found to be a suitable technique to solve the problem. Self Organizing Map (SOM) a type of Artificial Neural Network (ANN) used to solve this classification problem. For this study, lot of speed data is required for which GPS is found to be the most suitable method of data collection and hence extensively used. Free flow speed (FFS) and average travel speed during peak and off peak hours inventory of road segments are used in this study. FFS ranges for different urban Street Classes and speed ranges of LOS categories found to be lower than that mentioned in HCM-2000.
\end{abstract}

Keywords: Self Organizing Map (SOM), Artificial Neural Network (ANN), Level of Service (LOS), urban streets, GPS, clustering.

\section{Introduction}

Like every coin has two sides the urbanization also showing the consequences by taking toll on the urban infrastructure. Urban streets are not spared from the ill effect of urbanization. As a result, the operating condition of road available to the commuter decreases day by day. The operating conditions within a traffic stream and their perception by motorists and passengers are described as Level of Service (LOS) in HCM (2000). The HCM designates six levels of service for each type of facility, from A to $\mathrm{F}$, with LOS " $\mathrm{A}$ " representing the best operating conditions and LOS " $F$ " the worst. Each LOS corresponds to a particular set of operation condition as defined by HCM (2010). These conditions are more suitable for homogenous traffic of developed country. For developing country where the vehicles plying on road have different operational and physical characteristics the LOS is not well defined. Defining LOS is very much important because it helps in allocation of the limited financial resources to various competing projects.

\footnotetext{
${ }^{1}$ Corresponding author: smrutisourava@mail.iitbbs.ac.in
} 
Baumgaertner (1996), Cameron (1996), Maitra et al. (1999) and Brilon (2000) tried to find out the limitations of the current LOS measure. Alternatives like expanding the six LOS to more number of LOS categories have been suggested by the researchers. Kita and Fujiwara (1995) stated LOS not just as a traffic operating condition but tried to find the relationship of LOS with driver's perception. Spring (1999) raised question mark over LOS being a step function. He found service quality being a continuous and subjective matter so it is not wise to use a distinct boundary or threshold value for determining a particular level of service. Kittelson and Roess (2001) pointed out that the current methodology of determining LOS is not based upon user perception. Clark (2008) raised question mark about the LOS " $F$ " stating it to be very broad. He suggested for a new LOS to be termed as F+ or G. This study specially refers to the type of traffic condition prevailing in New Zealand. These are some previous studies which gave a background to this research to define the LOS in a more relevant way especially for Indian heterogeneous traffic.

Urban street level of service is primarily a function of travel speed along segments, and is calculated from field data (HCM). Floating car method is the most common technique to acquire speed data. In this method as a driver drives the vehicle, a passenger records the elapsed time information at predefined check points. This method is very much susceptible to human error (Turner et al., 1998). With improvement computers Distance Measuring Instrument (DMI) came as the solution of Floating car method for measurement of the speed distance using pulses from a sensor attached to the test vehicle's transmission (Quiroga and Bullock, 1998). Turner et al. (1998),
Benz and Ogden (1996) found limitation in this method relating to installation of the DMI unit and data storage problems. The development of Information Technology and advancement of Global Positioning System (GPS) has largely overcome the data quality and quantity shortcomings of the manual and DMI methods of collecting travel time data and become one of the alternatives to moving car observer method for field data collection.

After getting the speed data by using Trimble Geo XT GPS receiver, clustering technique is employed to classify urban streets into various classes as well as to determine the speed ranges of different LOS categories. Bhuyan and Rao (2010) used Fuzzy C-Means clustering technique in defining the free flow speed ranges of urban Street Classes and speed ranges of LOS categories in Indian context.

The capability of ANN in the application of various classification problems in traffic engineering is discussed. Lingras (1995) compared Hierarchical Agglomerative Clustering and the Kohonen Neural Network methods for classification of statically data. He found that Kohonen Neural Network is especially useful for classifying large amount of data while Hierarchical Agglomerative clustering is useful for small sample of data. Al-Garni and Abdennour (2008) developed a classification technique using ANN to detect and count the vehicles plying on road from the video images. Yang and Qiao (1998) applied Self Organizing Map of Artificial Neural Network for the pattern recognition of traffic flow states into some distinctive clusters. The accuracy of prediction of traffic volume of future traffic improved significantly with this combined algorithm. Jian-ming (2010) developed a combined ANN and Genetic Algorithm method for the prediction of traffic 
volume in Sanghai Metropolitan Area. The accuracy of prediction of traffic volume of future traffic improved significantly with this combined algorithm. Cetiner et al. (2010) developed a back propagation Neural Network traffic flow model for prediction of traffic volume of Istanbul City. The model uses the historical data at major junctions of the city for prediction of future traffic volume. Florio and Mussone (1995) have taken the advantage of application of ANN in classification problem to develop the flow-density relationship of a motorway. The author defined the stability and instability of spacing of vehicle in traffic stream. Murat and Baskan (2006) used ANN for determination of non uniform delay which is part of total vehicular delay at signalized intersections. Sharma et al. (1994) studied and compared the learning ability of both supervised and unsupervised type of learning method for clustering. Self Organizing Map (SOM) is a type of ANN which can learn to detect regularities and correlations in their input and responses in future accordingly.)

In this study a methodology has been developed for defining speed ranges of LOS categories of urban Street Classes using Artificial Neural Network. Urban streets are classified into different classes on the basis of the free flow speed. Average travel speed on urban street segments and their functional and geometric characteristics is used as the measure effectiveness for accessing LOS. The average travel speed data was derived from second by second speed data collected using Global Positing System (GPS). The speed data were acquired from five major corridors of Mumbai city which comprises a length of $140 \mathrm{~km}$. For each corridor 10 to 12 travel run were made during various time of the day comprising of both peak and off peak hours. Total five corridors were divided into 100 segments which are operating under mix traffic. Two urban street corridors of Kolkata City having varying geometric and surrounding environmental characteristics were also taken into considerations to find the applicability of this study for other cities of India. Out of the two corridors considered. one corridor was Airport to Joka and the other corridor was Airport to Ulberia. These two corridors are approximately $80 \mathrm{~km}$ long; comprised of 50 street segments. The interesting fact on selecting these two cities for this study is that traffic composition and road geometric characteristics along with functionality brings the true variation that was required for this purpose.

The measures of LOS, which describe the characteristics of traffic conditions under operation, include travel speed, traffic flow rate, and traffic density, for each type of road. These measures are useful to evaluate and compare the LOS of road sections of the same type. Similar to HCM 2000, average travel speed on street segments is taken as the Measure of Effectiveness (MOE) in defining LOS criteria of urban Street Classes in this study. It is presumed that speed is such a measuring parameter of traffic flow that when it varies, the service quality of the road segment automatically gets changed. The difference is that in HCM 2000 average travel speed on street segments is computed from running times on urban streets and control delay of through movements at signalized intersections taken from field measurements whereas in this case GPS has been employed for the collection of travel speed data directly from which average travel speed is computed. For clustering of speed data ANN is utilized twice, first, the free flow speed data were clustered to determine the urban Street Class of each segment. After determination of the 
urban Street Class of each segment average travel speed in peak and off peak hour is used in clustering methods to determine the speed ranges of LOS categories. SOM algorithm of ANN which utilizes the unsupervised type of learning is found to be good for clustering data. So in this research work SOM algorithm is used for clustering purpose. The following section provides brief review of the Artificial Neural Network Clustering technique and its validation measure. The remaining three sections describe the study corridors and methods of data collection, analysis of the collected data, results obtained, summary and conclusions.

\section{Artificial Neural Network (ANN)}

Artificial Neural Networks (ANN) is the result of academic investigations that use mathematical formulations to model nervous system operations. The resulting techniques are being successfully applied in a variety of everyday business application. ANN is used to learn pattern and relationship in data. The ANN mimics the human ability to adapt to changing circumstances and the current environment. They learn from the events that have happened in past to apply this knowledge to future environment. ANN consists of many nodes i.e. processing unit analogous to neuron in the brain. Each node has a node function and also some local parameters. Modification of local parameter changes the node function. Neural network may be of single or multiple layers. Single layer consists of input neurons and output neurons. Multi layer artificial neural network consists of input layer, output layer and hidden layer. There are various types of ANN like Feed forward neural network, Radial basis function network, Self-organizing Map (SOM), recurrent neural network. For this study, SOM which is best among ANNs for clustering of data is used.

\subsection{Self Organizing Map (SOM)}

A self-organizing map is a type of artificial neural network that is trained using unsupervised learning to produce a low-dimensional (typically two-dimensional) map. Self-organizing maps are different from other artificial neural networks in the sense that they use a neighborhood function to preserve the topological properties of the input space.

A self-organizing map consists of nodes. A weight vector is associated with each node and the weight vector is of the same dimension as the input data vectors. The usual arrangement of nodes is a regular spacing in a hexagonal or rectangular grid. The self-organizing map describes a mapping from a higher dimensional input space to a lower dimensional map space. The procedure for placing a vector from data space onto the map is to first find the node with the closest weight vector to the vector taken from data space. Once the closest node is located it is assigned the values from the vector taken from the data space.

\subsubsection{Architecture of $A N N$ and Parameters Used}

The architecture of the ANN is shown in Fig. 1. SOM algorithm is used in this research to train the Input data. SOM basically has 2 layers architecture, containing Input and Output layer. The input layer contains nodes, through which input data is given to the neural network. The number of nodes varies according to the dimension of input data set. In this study the input layer contains 100 nodes because FFSs data of 100 segments are utilized for training of neural network. Each node is associated with a weight vector which changes in every iteration during training process. The output layer contains neurons and each neuron 
corresponds to the centroid of a particular cluster. The shape of the neuron depends upon the topology function. In this study hexagonal topology was chosen.

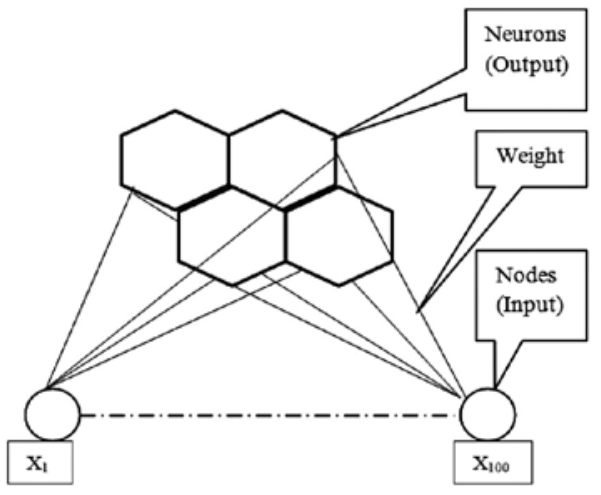

Fig. 1.

A Self Organizing Map (SOM) Neural Network

In Table 1 details on parameters used in SOM are shown.

Table 1

Parameters Used in SOM

\begin{tabular}{|c|c|}
\hline Parameter & Detail \\
\hline Topology Function & HEXTOP \\
\hline Distance Function & LINKDIST \\
\hline Learning Rate & 0.9 \\
\hline Iterations for training & 100 \\
\hline Neighborhood Distance & 1.0 \\
\hline
\end{tabular}

\section{SOM Clustering and Validation Measure}

\subsection{SOM Clustering}

Among various types of ANN algorithms, in this study Self Organizing Map is used for clustering of speed data because of its inherent capability to learn the pattern of input. SOM is trained iteratively being inspired by neural networks in the brain. Self Organization Map (SOM) uses a competition and cooperation mechanism to achieve unsupervised learning. In SOM, a set of nodes is arranged in a geometric pattern which is typically a 2-dimensional lattice. This arrangement of neuron may be grid, hexagonal or random topology. In this research Hexagonal topology is used. Each node is associated with a weight vector with the same dimension as the input space. The purpose of the SOM is to find a good mapping. During training, each node is presented to the map so the input data is also associated with it. An input weight vector of same dimension as that of input data dimension was given to the ANN. The clustering using SOM algorithm was done in two steps.

\section{STEP 1:}

The input data is compared with all the input weight vectors $m_{i}(t)$ and the Best Matching Unit $(B M U)$ on the map is identified. The $B M U$ is the node having the lowest Euclidean distance with respect to the input pattern $x(t)$. The final topological organization of the map is heavily influenced by this distance. $B M U m_{c}(t)$ is identified by Eq. (1):

For all $i,\left\|x(t)-m_{c}(t)\right\| \leq \| x(t)-m_{i}(t)$

\section{STEP 2:}

Weight vectors of BMU are updated as Eq. (2):

$$
m_{i}(t+1)=m_{i}(t)+\alpha h_{b(x) i}\left(x(t)-m_{i}(t)\right)
$$

Here $h_{b(x)}$ is the neighborhood function, which is Eq. (3): 


$$
h_{b(x)}=\alpha(t) e^{\left(-\frac{\left\|r_{i}-r_{b(x)}\right\|^{2}}{2 \sigma^{2}(t)}\right)}
$$

Where $0<\alpha(t)<1$ is the learning rate factor which decreases with each iteration. $r_{i}$ and $r_{b(x)}$ are the locations of neuron in the input lattice. $\alpha(t)$ defines the width of the neighborhood function. The above two steps were repeated iteratively until the pattern in input was processed.

\subsection{Validation Measure}

Cluster validity is concerned with checking the quality of clustering results. It has been mainly used to evaluate and compare whole partitions, resulting from different algorithms or resulting from the same algorithms under different parameters. Common application of cluster validation measure is to determine the correct number of cluster for a set of data (Bensaid et al., 1996). Different validity measures have been proposed in the literature, none of them is perfect by oneself, and therefore several indices are used in this study, such as: C-index, Weighted inter-intra index, Hartigan index, R-squared Index, KrzanowskiLai Index and Davies-Bouldin Index.

\section{A) C-index}

The C-index is defined as Eq. (4):

$$
\frac{s-s_{\min }}{s_{\max }-s_{\min }}
$$

Where $S$ is the sum of distances over all pairs of objects form the same cluster, $\mathrm{n}$ is the number of those pairs and $S_{\text {min }}$ is the sum of the $n$ smallest distances if all pairs of objects are considered. Likewise $S_{\max }$ is the sum of the $\mathrm{n}$ largest distances out of all pairs. Hence a small value of $C$ indicates a good clustering.

\section{B) Weighted inter-intra index}

This index tries to find the optimal number of cluster by high overall quality of cluster and a small number of cluster $k$. The quality of cluster is determined as follow (Eq. (5)):

$\phi^{(Q)}(X, \lambda)=1-\frac{\sum_{i=1}^{n_{i}} \frac{n_{i}}{n-n_{i}} \sum_{j \in\{1, \ldots i-1, i+1 \ldots k\}} n_{j} \times \operatorname{inter}(X, \lambda, i, j)}{\sum_{i=1}^{k} n_{i} \times \operatorname{intra}(X, \lambda, i)}$

Where (Eq. (6)):

$\operatorname{inter}(X, \lambda, i, j)=\frac{1}{n_{i} \mathrm{X} n_{j}} \sum_{\lambda_{a}=i, \lambda_{b}=j} S\left(X_{s}, X_{b}\right)$

And (Eq. (7)):

$\operatorname{intra}(X, \lambda, j)=\frac{2}{\left(n_{i}-1\right) \mathrm{X} n_{i}} \sum_{\lambda_{a}=\lambda_{b}=i, b>a} S\left(X_{a}, X_{b}\right)$

Here $i$ and $j$ are cluster indices. $X_{a}$ and $X_{b}$ are two vertices.

\section{C) Hargitan index}

For a clustering result with $k$ clusters, the overall fitness for the clustering can be expressed as the square of the error for all samples (Eq. (8)):

$$
\operatorname{err}(k)=\sum_{i=1}^{k} \sum_{j=1, j \in C_{i}}^{N} d^{2}\left(X_{j}, X_{c_{i}}\right)
$$

Where $N$ is the number of data points, where $X_{i}$ is an M-component vector, representing $\mathrm{M}$ features for sample $I$; $d$ is the distance between data sample $X_{j}$ and the centre $X_{\mathcal{C}_{i}}$.

Then, Hartigan index $H(k)$, for $k$ partitioning, is expressed as follow (Eq. (9)):

$$
H(k)=(n-k-1) \frac{\operatorname{err}(k)-\operatorname{err}(k+1)}{\operatorname{err}(k+1)}
$$




\section{D) R-squared index}

R-squared index (RS) is defined as follow (Eq. (10)):

$\mathrm{RS}=\frac{S S_{t}-S S_{w}}{S S_{t}}$

Where (Eq. (11)):

$S_{t}=\sum_{j=1}^{d} \sum_{k=1}^{n_{j}}\left(x_{k}-\overline{x_{j}}\right)^{2}$ and $S S_{w}=\sum_{\substack{i=1 \\ j=1, \ldots, n_{d}}} \sum_{k=1}^{n_{i j}}\left(x_{k}-\overline{x_{j}}\right)$

Here $d$ is number of clusters, $n_{c}$ is optimum number of cluster, $n_{j}$ is Number of element in $j^{\text {th }}$ dimension in the whole data set, $\overline{x_{j}}$ is expected value in $j^{\text {th }}$ dimension, $n_{i j}$ is the Number of elements in $i^{\text {th }}$ cluster $j^{\text {th }}$ dimension.

\section{E) Krzanowski-Lai (KL) index}

The index of Krzanowski and Lai is defined by Eq. (12):

$$
K L(k)=\left|\frac{\operatorname{DIFF}(k)}{\operatorname{DIFF}(k+1)}\right|
$$

Where (Eq. (13)):

$\operatorname{DIFF}(k)=(k-1)^{2 / p} W(k-1)-k^{2 / p} W(k)$

and $p$ denotes the number of features in the data set, $k$ denotes the number of clusters, $W(k)$ denotes the within cluster sum of square of the partition.

\section{F) Davies-Bouldin (DB) index}

This index is a function of the ratio of the sum of within-cluster scatter to between-cluster separation.
This DB index is defined by Eq. (14):

$D B=\frac{1}{n} \sum_{i=1}^{n} \max _{i \neq j}\left\{\frac{S_{n}\left(Q_{i}\right)+S_{n}\left(Q_{j}\right)}{S\left(Q_{i}, Q_{j}\right)}\right\}$

Where $n$ is number of clusters, $S_{n}\left(Q_{i}\right)$ and $S_{n}\left(Q_{j}\right)$ are average distances of all objects from the cluster to their cluster centre, $S_{n}$ $\left(Q_{i}\right),\left(Q_{j}\right)$ is distance between cluster centers. So, when the cluster is compact and far from each other the ratio is small. Consequently Davies-Bouldin index is small for good cluster.

\section{Study Corridor and Data Collection Techniques}

\subsection{Study Corridor}

For this study the commercial capital of India Mumbai City was considered. The city has linear pattern of transport network having predominant North-South commuter movements. South Mumbai houses various work place so during morning time people move towards South for work and during evening hours they returns towards north to their homes in the Suburbs of Mumbai. In this study five major corridors were chosen out of which four are North-South corridors and one is East-West corridor. The NorthSouth corridors are Eastern express highway extending up to South (Corridor-1), LBS Road extending up to South via Ambedkar road (Corridor-2), Western express highway extending up to marine drive (Corridor-3), $S V$ road extending up to South via Veer Savarkar road (Corridor-4) and the only East-West corridor is Versova - Andheri Ghatkopar - Vashi (VAGV) (Corridor-5). These five corridors are overlapped on the GIS base map of Greater Mumbai and are shown in Fig. 2. Two urban street corridors of Kolkata city, which is in the eastern part of 


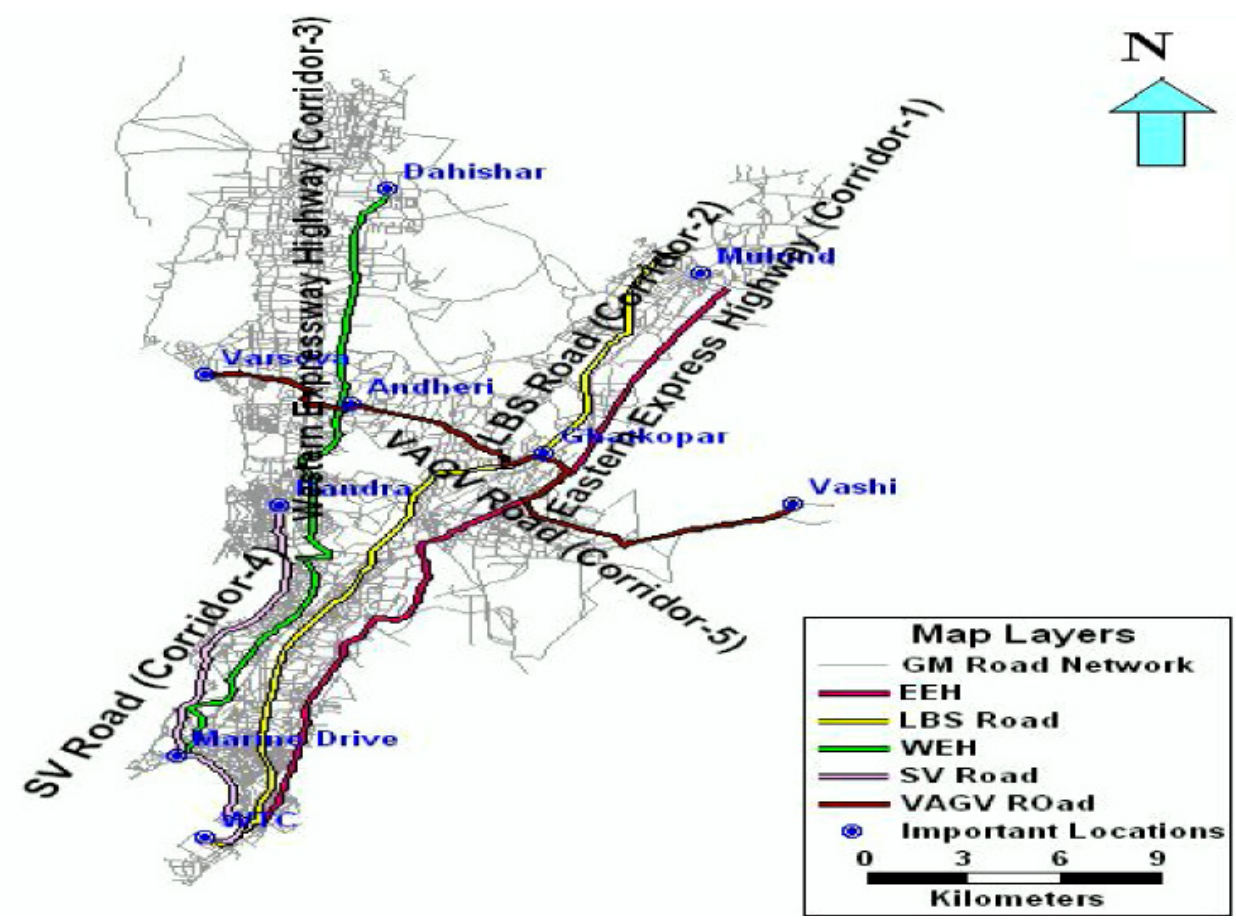

Fig. 2.

Map Showing Selected Corridors of Greater Mumbai

India, were studied to find the applicability of this research in other Indian cities. These two corridors studied for this research are Airpot to Joka and Airpot to Ulberia.

\subsection{Data Collection}

Trimble Geo-XT GPS receiver which logs data continuously in a time interval of one second was fitted to a mid-sized vehicle, typically a car. The data acquired by GPS provide both spatial and temporal references from which various traffic parameters were derived, including travel time and travel speeds. In order to get unbiased data sets three midsized vehicles were used and help of different drivers on different days of the survey work was taken. Basically three types of data sets were collected. The first type is roadway inventory details. In this survey details on segments like segment number, number of lanes, median types, pedestrian activity, road side development, access density, construction activity, speed limit, separate right turn lane, number of flyovers, date and day of data collection and segment length were collected. During the collection of inventory details, proper segmentation technique was applied, which is the directional stretch of road section immediately after signalized intersections to the location point immediately after the next signal. The second type of survey was to find the free flow speed. Before finding the free flow speed data a detailed 24 hours traffic count survey conducted at 45 stations on 7 screen lines to know the duration in a day when traffic volume is less than or equal to 200 vehicle per lane per hour. It was found that 

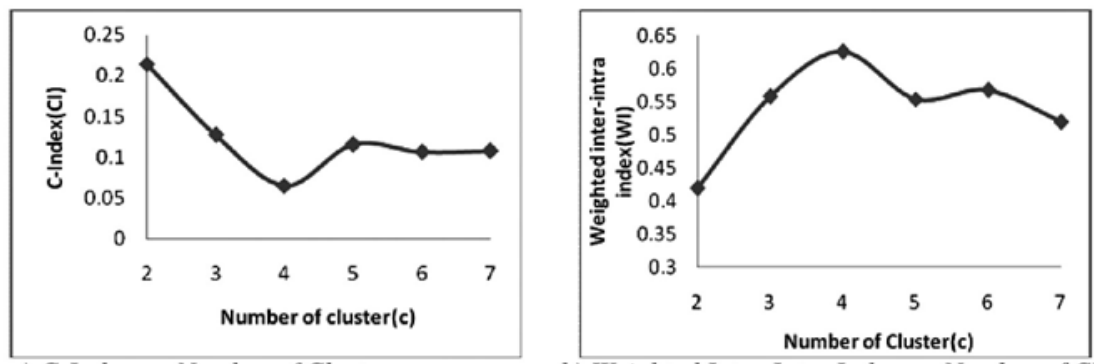

a) C-Index vs. Number of Cluster

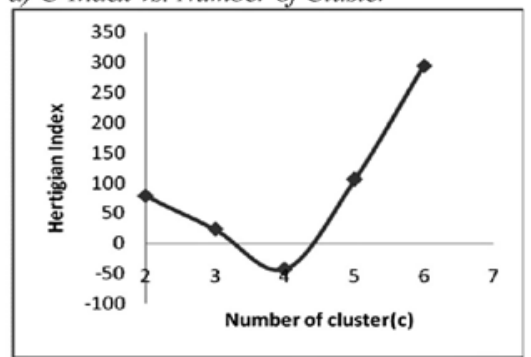

b) Weighted Inter-Intra Index vs. Number of Cluster

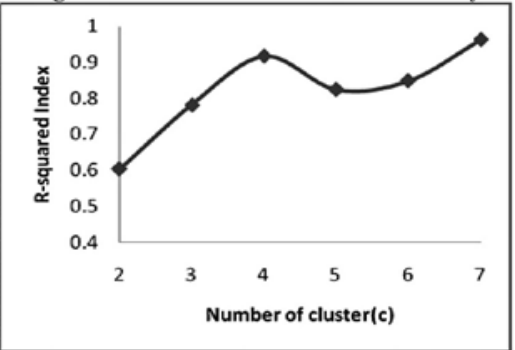

c) Hertigian Index vs. Number of Cluster
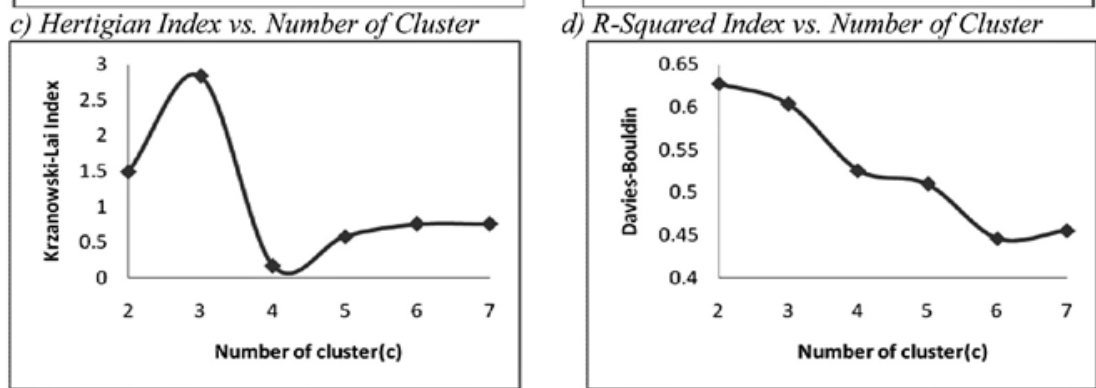

e) Krzanowski-Lai Index vs. Number of Cluster f) Davies-Bouldin Index vs. Number of Cluster

Fig. 3.

Validation Measures for Optimal Number of Clusters Using ANN Clustering

free flow traffic condition (less than 200veh/ $\ln / \mathrm{hr}$ ) is approaching at 12 midnight and all road sections are having free flow traffic conditions from $1 \mathrm{AM}$ to $5 \mathrm{AM}$. Hence free flow speed for all these corridors were collected during these hours. The third type of data collected was congested travel speed. Number of trips covered for each direction of travel and for the study hours (peak, off-peak and free-flow) is at least 3 and sometimes it is up to six trips. Relevance of the current study was further strengthened by considering the traffic of Kolkata city which is in the eastern part of India. Two corridors having varying geometric and surrounding environmental characteristics were taken into considerations i.e. one corridor was Airport to Joka and the other corridor was Airport to Ulberia. These two corridors are approximately $80 \mathrm{~km}$ in length; comprised of 50 street segments. The true variation required for the purpose was brought by studying the traffic composition and road geometric characteristics of the two cities. 


\section{Results and Analysis}

The free flow speed data acquired through GPS receiver was clustered using the SOM algorithm of ANN. For determination of the parametric value of validation measures, free flow speed data and cluster centre found from ANN analysis were used. In this research six validation parameters were used. Value of validation parameters were obtained for 2 to 7 number of cluster and were plotted in Fig. $3 a$ to Fig. $3 f$.

These six numbers of validation parameters were used to know the optimum number of cluster for this particular data set of free flow speed. By knowing the optimum number of cluster we can classify the urban street segments into that number of Urban Street Classes. It is always considered that lesser number of clusters is better if variation in validation parameters is minimal. Literature says that the lowest value of C-Index (CI) and Hertigian Index (HI) signifies the optimal number of cluster for a particular set of data. Fig. 3a and Fig. $3 \mathrm{c}$ show that the index is lowest for 4 number of cluster. Also, available literature says that the highest value of Weighted Inter-Intra Index (WI) gives the optimal number of cluster for a given data set, which is 4 as shown in Fig. 3b. For R-squared Index (RI), the optimal number of cluster is that point from where the Index vs. Number of cluster graph goes downward.

Fig. $3 \mathrm{~d}$ shows the R-squared Index goes downward beyond four clusters; this goes in hand with $\mathrm{CI}, \mathrm{HI}$ and WI giving the optimal number of cluster as 4 . The highest value of Krzanowski-Lai index (KI) gives the optimal number of cluster. From Fig. 3e it can be seen that $\mathrm{KI}$ is highest for 3 numbers of cluster. Davies-Bouldin index (DI) is shown in Fig.
$3 \mathrm{f}$ for which the optimal number of cluster is the point at which the index value is the lowest one and found to be 6 . Out of six validation parameters considered in this study four parameters give the optimal cluster value as 4 which are also same as suggested by HCM (2000). That is the reason for which in this research the urban street segments were classified into four Classes by using the SOM in ANN.

In this study, 100 urban street segments of five urban street corridors were analyzed. So to get the FFS ranges of different urban Street Class FFS of these 100 urban street segments were clustered using ANN. Self Organizing Map (SOM) which is known to be the best neural network for clustering data was utilized for this purpose. To cluster these FFS data four neurons were used in the SOM which acted as the centroid of a particular cluster. The SOM sample hit plot is shown in Fig. 4. This figure shows clustering of FFS data around each neuron that acted as a centroid. As a hexagonal topology has been considered, the neurons are shaped as hexagon. The number inside the hexagon depicts the amount of data associated with a particular cluster. From Fig. 4 it can be seen that two clusters have more numbers of data than the other two clusters.

Fig. 5 shows the speed ranges for different urban Street Classes. Different symbol in the plot is used for different urban Street Class. Observing these two figures, it can be inferred that most of the street segments belong to Urban Street Class-I and Urban Street ClassII. In SOM sample hit plot hexagon with larger value corresponds to Urban Street Class-I and Urban Street Class-II. It is observed from the collected data set that when a street segment falls under particular urban street, class is agreed with the geometric and surrounding 


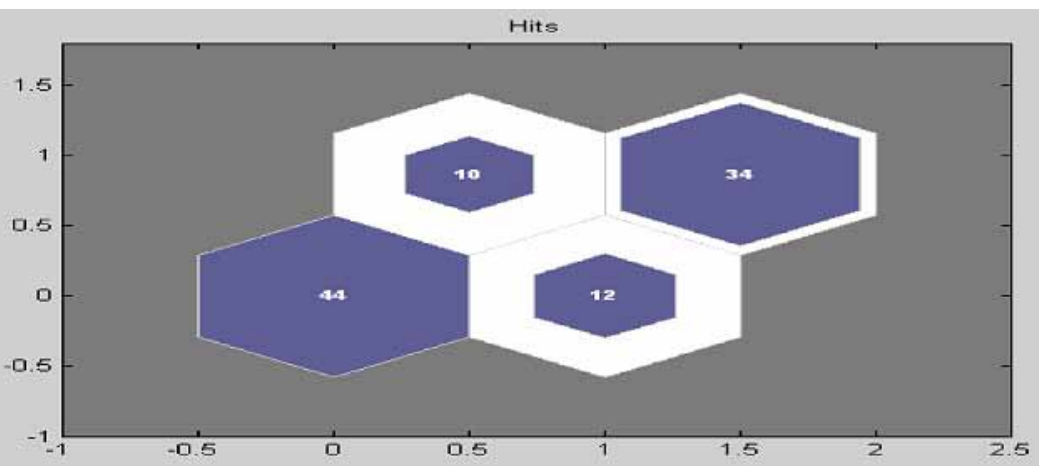

\section{Fig. 4.}

SOM Sample Hit Plot

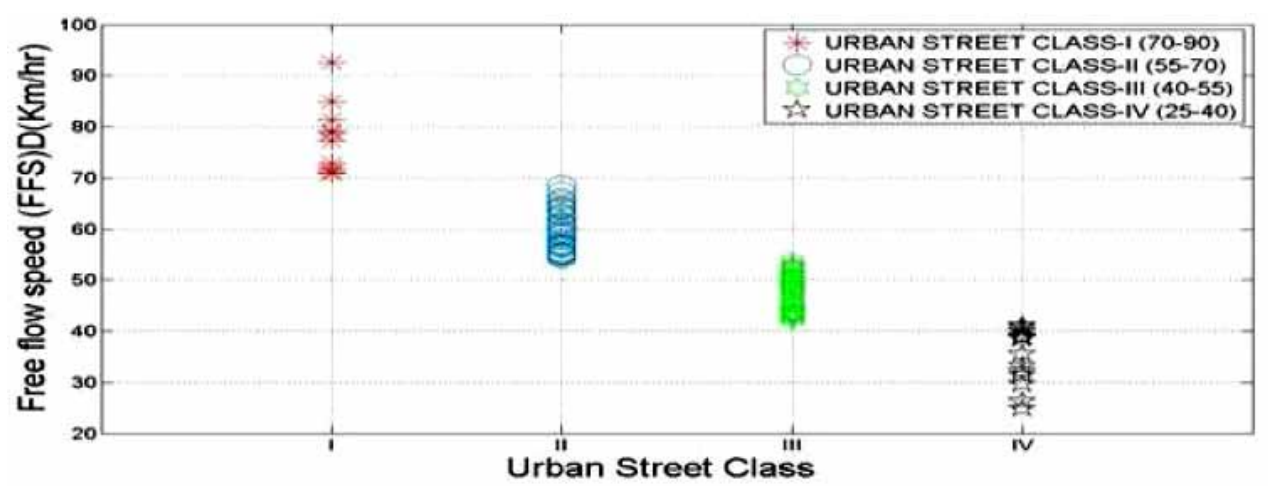

Fig. 5.

ANN Clustering of FFS for Urban Street Classification

environmental condition of the road segments as well. It has been found that there is very good correlation between free flow speed and geometric and environmental characteristics of streets under considerations.

After classification of urban streets into number of classes, direction wise average travel speed on street segments during both peak and off peak hours were clustered using ANN to find the speed range of level of service categories. In Fig. 6 the speed values are shown by different symbols depending on to which LOS category they belong. The legends in Figs. 6a-6d give the speed ranges for the six LOS categories obtained by using ANN clustering. The speed ranges for LOS categories found using ANN clustering is also shown in Table 2.

Free flow speed ranges for urban Street Class IV for the present context are found to be 25 $\mathrm{km} / \mathrm{h}$ to $35 \mathrm{~km} / \mathrm{h}$; whereas, $40 \mathrm{~km} / \mathrm{h}$ to 55 $\mathrm{km} / \mathrm{h}$ are the values mentioned in HCM 2000. Similarly, $10 \mathrm{~km} / \mathrm{h}$ or less is the speed value shown in Table 2 for level of service category "F" under urban Street Class IV; whereas, 14 $\mathrm{km} / \mathrm{h}$ is the corresponding value mentioned in HCM 2000. Applying this method it is found that both free flow speed ranges for urban 


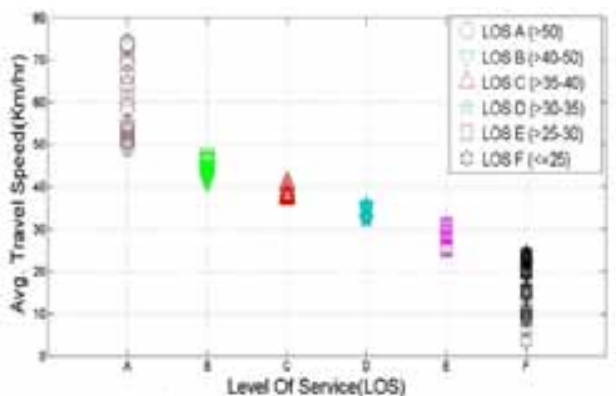

a) LOS of Urban Sireer Class I

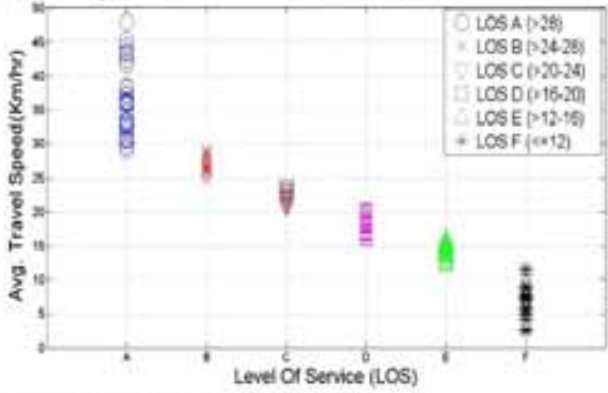

c) LOS of Urban Street Class III

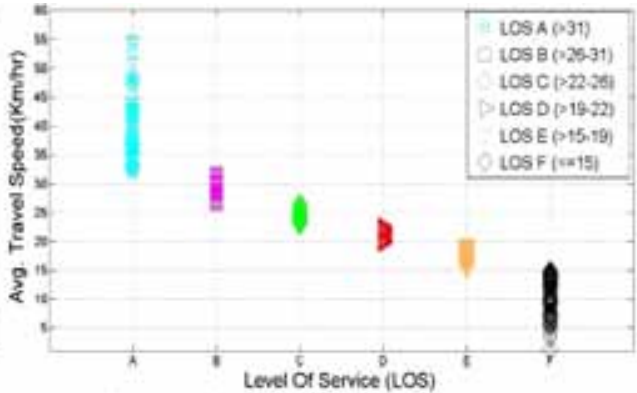

b) LOS of Urban Street Class II

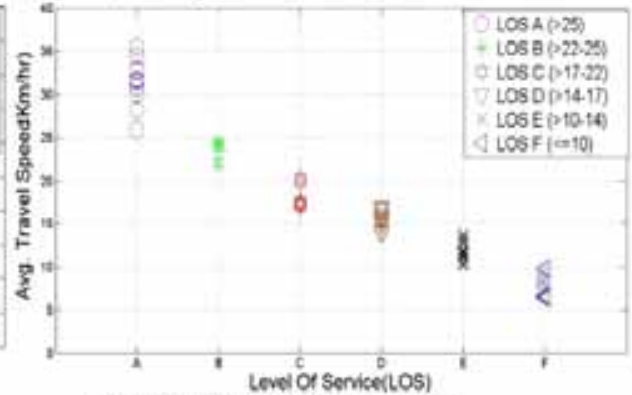

d) LOS of Urban Street Class IV

Fig. 6.

Level of Service of Urban Street Classes (I-IV) Using ANN Clustering on Average Travel Speeds

Table 2

Urban Street Speed Ranges for Different LOS Proposed in Indian Conditions by ANN Method

\begin{tabular}{|c|c|c|c|c|}
\hline Urban Street Class & I & II & III & IV \\
\hline $\begin{array}{c}\text { Range of Free Flow } \\
\text { Speed (FFS) }\end{array}$ & 63 to $85 \mathrm{~km} / \mathrm{h}$ & 46 to $63 \mathrm{~km} / \mathrm{h}$ & 35 to $46 \mathrm{~km} / \mathrm{h}$ & 25 to $35 \mathrm{~km} / \mathrm{h}$ \\
\hline Typical FFS & $68 \mathrm{~km} / \mathrm{h}$ & $54 \mathrm{~km} / \mathrm{h}$ & $42 \mathrm{~km} / \mathrm{h}$ & $32 \mathrm{~km} / \mathrm{h}$ \\
\hline LOS & \multicolumn{3}{|c|}{ Average Travel Speed $(\mathbf{K m} / \mathbf{h})$} & $>25$ \\
\hline A & $>50$ & $>31$ & $>28$ & $>22-25$ \\
\hline B & $>40-50$ & $>26-31$ & $>20-24$ & $>17-22$ \\
\hline C & $>35-40$ & $>22-26$ & $>16-20$ & $>14-17$ \\
\hline D & $>30-35$ & $>19-22$ & $>12-16$ & $>10-14$ \\
\hline E & $>25-30$ & $>15-19$ & $\leq 12$ & $\leq 10$ \\
\hline
\end{tabular}


Street Classes and speed ranges for level of service categories are significantly different from those values mentioned in HCM 2000. The speed ranges for LOS categories (A-F) expressed in percentage of FFS are found to be approximately 80 or above, $62-80,48-62$, $35-48,23-35$ and 23 or lower respectively in the present study. Whereas, in HCM (2010) it has been mentioned these values are 85 or above, $67-85,50-67,40-50,30-40$ and 30 or lesser percent respectively.

In order to check the application of this level of service criteria; data collected from
Kolkata city were tested. Free flow speed and average travel speed during both peak and off-peak hours on each of segments on both corridors were calculated. The street segments were classified into four classes based on free-flow speed, geometric and surrounding environmental characteristics. Also, levels of service provided by the street segments during peak and off peak hours were estimated using Table 2. The percentage of travel runs under different levels of service categories found for urban Street Classes in Kolkata city during the survey period are shown in Table 3.

Table 3

Percentage of Travel Runs under Levels of Service Categories of Urban Street Classes in Kolkata City

\begin{tabular}{|c|c|c|c|c|}
\hline \multirow{2}{*}{ Level of Service } & \multicolumn{4}{|c|}{ Urban Street Class } \\
\cline { 2 - 5 } & I & II & III & IV \\
\hline A & 61.11 & 38.89 & 14.58 & 40.00 \\
\hline B & 16.67 & 5.56 & 18.75 & 6.67 \\
\hline C & 8.33 & 5.56 & 14.58 & 11.11 \\
\hline D & 0.00 & 16.67 & 8.33 & 8.89 \\
\hline E & 0.00 & 16.67 & 18.75 & 15.56 \\
\hline
\end{tabular}

From this table it has been seen that the observed vehicle travelled at better quality of service under urban Street Class I, whereas under other urban Street Classes the observed vehicle travelled at medium quality of service during the observed period. The basic inference that can be drawn from this part is that the probe vehicle covered on road segments has very long mid-block sections and heavily loaded intersections. Further it can be deducted that roadside development and side frictions due to pedestrians' movements and vendor's activity are comparatively low on these sections.

The coherence of the clustering result in the classification of urban streets into four classes and speed values into six LOS categories are verified with the road inventory data that were collected during survey. The road inventory data considered here are number of lanes, median type, access density, road side development, on street parking and pedestrian activity. These geometric characteristics and surrounding environmental characteristics provides sufficient information on physical characteristics of each road segments. Out of the five urban street corridors, physical characteristics of street segments under urban street Corridor- 3 are shown in the Table 4 for information. Table 4 contains various geometric and surrounding environmental characteristics of 15 street segments of Urban Street Corridor-3 that were acquired during inventory survey and also the different LOS experienced on these street segments. Geometric and surrounding environmental characteristics were checked to know whether 


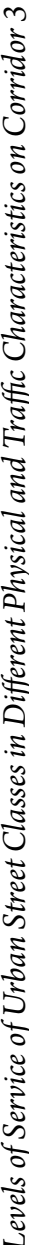

\begin{tabular}{|c|c|c|c|c|c|c|c|c|c|c|c|c|c|c|c|c|}
\hline \multirow{8}{*}{ 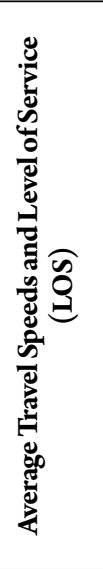 } & $\tilde{o}$ & $u$ & $\infty$ & $\varangle$ & $\varangle$ & $\infty$ & $\varangle$ & u & $\varangle$ & a & 띠 & 디 & $u$ & 工 & $\infty$ & 工 \\
\hline & 我 的 $Z$ & $\stackrel{m}{m}$ & $\stackrel{?}{\stackrel{n}{\sim}}$ & $\begin{array}{l}\dot{\sigma} \\
\dot{+}\end{array}$ & $\stackrel{m}{\infty}$ & $\begin{array}{l}b \\
\dot{f}\end{array}$ & $\dot{0}$ & ث্ & $\begin{array}{c}0 \\
\infty \\
+\infty \\
\end{array}$ & $\begin{array}{l}\sim \\
\stackrel{1}{0} \\
\end{array}$ & $\begin{array}{l}a \\
\dot{n}\end{array}$ & \begin{tabular}{l|}
0 \\
0 \\
-1 \\
\end{tabular} & 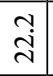 & $\stackrel{\infty}{\infty}$ & $\hat{\sim}$ & $\begin{array}{l}m \\
\infty \\
\infty\end{array}$ \\
\hline & రి & a & $u$ & $\varangle$ & $\varangle$ & $\varangle$ & 디 & A & $\infty$ & $\infty$ & 山 & $\varangle$ & $\infty$ & 디 & $\varangle$ & 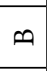 \\
\hline & 山' & $\begin{array}{l}n \\
0 \\
0 \\
\tilde{n}\end{array}$ & $\stackrel{n}{\stackrel{\sim}{d}}$ & $\stackrel{g}{\dot{f}}$ & $\stackrel{亏}{\vec{F}}$ & t. & 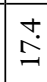 & $\dot{\vec{v}}$ & 忿 & 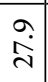 & $\overrightarrow{\mathrm{j}}$ & $\stackrel{+}{\dot{f}}$ & 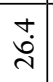 & $\stackrel{?}{=}$ & $\frac{n}{m}$ & $\stackrel{+}{\stackrel{+}{d}}$ \\
\hline & $\tilde{o}$ & 뙤 & $\infty$ & $\varangle$ & $\varangle$ & $\varangle$ & 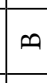 & $\varangle$ & $\infty$ & $\varangle$ & $\infty$ & $\theta$ & $\infty$ & 0 & $\varangle$ & $\theta$ \\
\hline & $\sum$ is $Z$ & $\mid \begin{array}{l}0 \\
0 \\
0\end{array}$ & $\overrightarrow{0}$ & $\stackrel{\sim}{\dot{f}}$ & $\overrightarrow{⿱ 乛}+$ & $\overrightarrow{0}$ & $\vec{\Lambda}$ & $\begin{array}{l}\text { Ij } \\
\text { ? }\end{array}$ & $\begin{array}{l}0 \\
\hat{i}\end{array}$ & $\begin{array}{l}\tilde{n} \\
\tilde{m} \\
\end{array}$ & $\begin{array}{l}-1 \\
\dot{p} \\
\end{array}$ & $\stackrel{?}{a}$ & $\begin{array}{l}0 \\
\dot{b} \\
i\end{array}$ & $\begin{array}{l}\infty \\
\text { in } \\
\text { ते }\end{array}$ & $n$ & $\stackrel{m}{2}$ \\
\hline & oి & 피 & 띠 & $\varangle$ & $\varangle$ & u & 띠 & 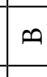 & $u$ & $\infty$ & 피 & $\theta$ & $u$ & $\varangle$ & 피 & 0 \\
\hline & $\sum^{\prime} \dot{z}^{\prime} \infty$ & 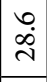 & $\stackrel{2}{2}$ & 安 & $\infty$ & مج & ఏ & ه্ঠ & $\begin{array}{l}y \\
\dot{s} \\
\end{array}$ & $\begin{array}{r}\stackrel{+}{\sim} \\
\end{array}$ & $\tilde{n}$ & \begin{tabular}{l|}
$\infty$ \\
$\dot{\vec{\lambda}}$ \\
\end{tabular} & $\begin{array}{l}n \\
\tilde{i} \\
\end{array}$ & $\begin{array}{c}\hat{\imath} \\
\dot{\lambda}\end{array}$ & & ㄱ. \\
\hline \multirow{3}{*}{ 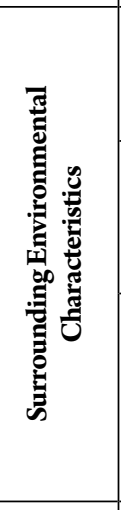 } & 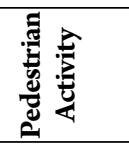 & $\begin{array}{c}0 \\
\tilde{D} \\
0 \\
\omega\end{array}$ & 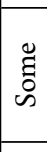 & 窇 & हี & हี & हี & $\begin{array}{l}\text { : } \\
\text { ڤे }\end{array}$ & 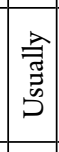 & 墨 & 墨 & 趌 & 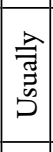 & 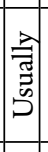 & 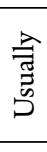 & 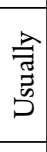 \\
\hline & 最 & 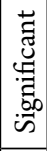 & 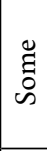 & ż & $\begin{array}{l}\text { हี } \\
\text { के }\end{array}$ & ż & ż & $\stackrel{\circ}{z}$ & 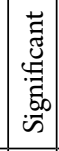 & 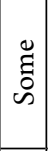 & 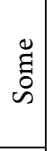 & 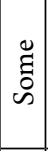 & 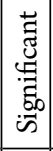 & 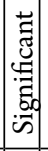 & 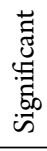 & 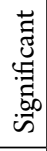 \\
\hline & 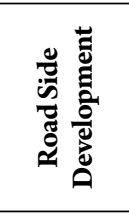 & 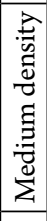 & 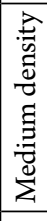 & 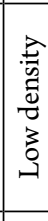 & 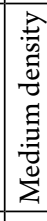 & $\begin{array}{l}0 \\
0 \\
0 \\
0 \\
0 \\
0 \\
0 \\
0\end{array}$ & $\begin{array}{l}3 \\
0 \\
0 \\
0 \\
0 \\
0 \\
0 \\
0 \\
.1\end{array}$ & $\begin{array}{l}0 \\
0 \\
0 \\
0 \\
0 \\
0 \\
0 \\
0 \\
.1\end{array}$ & 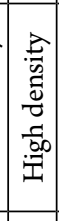 & 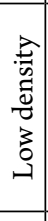 & 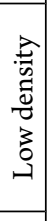 & $\begin{array}{c}3 \\
0 \\
0 \\
0 \\
0 \\
0 \\
3 \\
0 \\
-1 \\
-1\end{array}$ & 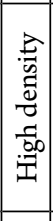 & $\mid \begin{array}{l}7 \\
0 \\
0 \\
0 \\
0 \\
0 \\
0 \\
0\end{array}$ & 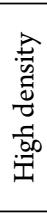 & 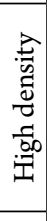 \\
\hline \multirow{4}{*}{ 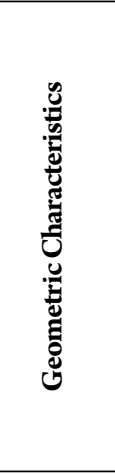 } & 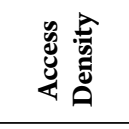 & $\mid$\begin{tabular}{|c|c}
3 \\
0 \\
-1 \\
\end{tabular} & \begin{tabular}{|l|}
3 \\
0 \\
1 \\
-1
\end{tabular} & | & 苟 & كَ. & 恋 & 急 & 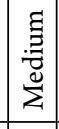 & 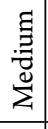 & 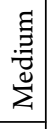 & 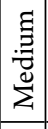 & 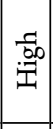 & 预 & $\begin{array}{l}50 \\
.00 \\
.07\end{array}$ & 需 \\
\hline & 宽 & 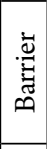 & 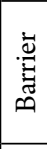 & $\stackrel{\vec{U}}{\mathscr{E}}$ & 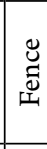 & $\stackrel{\vec{D}}{\mathscr{E}}$ & 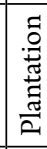 & 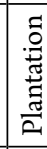 & 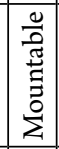 & 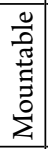 & 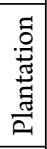 & $\ddot{z}$ & $\ddot{z}$ & $\stackrel{0}{z}$ & z & ż \\
\hline & छ & 10 & 9 & . & A & A & A & O & $\stackrel{9}{9}$ & A & $A$ & مُ & 곡 & |ح & 马્ડ & ב \\
\hline & 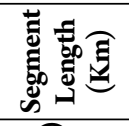 & i & $\stackrel{\infty}{-}$ & பே. & $\stackrel{?}{+}$ & $\stackrel{+}{+}$ & D & $\dot{s}$ & 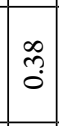 & $\frac{n}{\infty}$ & $\grave{o}$ & $\stackrel{+}{-}$ & 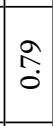 & ஸे & 0 & $\tilde{a}$ \\
\hline \multicolumn{2}{|c|}{ 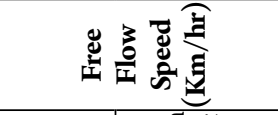 } & - & $\stackrel{n}{i}$ & ڤે & $\underset{\sim}{\sim}$ & $\stackrel{?}{\wedge}$ & in & $\begin{array}{l}\infty \\
\infty \\
\infty \\
\infty \\
n\end{array}$ & $\stackrel{\sim}{\stackrel{+}{+}}$ & $\stackrel{\substack{* \\
\dot{H}}}{ }$ & $\stackrel{+}{\dot{*}}$ & $\begin{array}{l}\hat{b} \\
i n\end{array}$ & $\stackrel{\circ}{\dot{y}}$ & $\mid \begin{array}{l}\dot{j} \\
\dot{\sim}\end{array}$ & $\vec{m}$ & רे \\
\hline \multirow{2}{*}{ 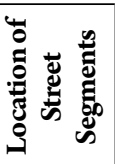 } & 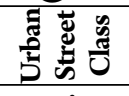 & -1 & $\Xi$ & $\Xi$ & 目 & 七 & ヨ & ヨ & 目 & $\exists$ & $\exists$ & $\exists$ & 目 & 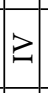 & Z & Z \\
\hline & હో & 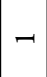 & $N$ & $m$ & $\checkmark$ & in & 0 & N & $\infty$ & $a$ & 으 & $\exists$ & $\simeq$ & $\stackrel{2}{-1}$ & \pm & - \\
\hline
\end{tabular}

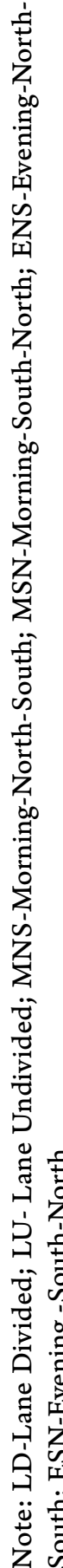


the experienced LOS on a particular road segment during a travel run actually satisfies to the field condition or not. From this analysis it is inferred that on a segment having good traffic flow, geometric and surrounding environmental conditions good LOS "A", "B", " $C$ ", can be experienced by the commuter. The commuter have to experience poor LOS like "D", "E", and " $F$ " when traffic flow condition is poor and surrounding environmental conditions are not so good. Therefore, travel speed parameter used to determine LOS is quite capable in defining LOS categories for a particular urban street segment.

\section{Conclusion}

From analyzing the six validation parameters it is well appropriate to classify the urban street into four urban classes (I-IV) in Indian context. The free flow speed ranges were found to be lower than that mentioned in HCM 2000. Road segments having varying geometric characteristics and haphazard road side development may be causes of these low FFS ranges. The speed range of each particular LOS category was found to be significantly lower than that mentioned in HCM 2000. Presence of Non-motorized vehicle (NMV) and slow moving motorized interference can be one of the major reasons for these lower values in free flow speed. Speed ranges of different LOS categories in terms of percentage free flow speed also found to be lower than that mentioned in HCM (2000). For LOS A speed range was found to be $80 \%$ of FFS which is $90 \%$ according to HCM (2010), because unwanted movement of pedestrians along and across the road sections produces undesirable side friction that constrain travelers to reduce vehicular speed. Road side vendors and onstreet parking occupy substantial portion of road sections which compels the commuter to move through a narrower space can also be inferred to be one of the reason. From the SOM in ANN clustering of FFS data it can be seen (from Fig. 5) less number of roads in Mumbai are of high speed design (Street Class I) or typical urban design (Street Class IV). More number of road segments is of suburban (Street Class II) or intermediate (Street Class III) type. It can be suggested that Greater Mumbai region needs substantial geometric improvements to mitigate the burden on urban road infrastructure because of ever growing vehicular traffic volume. From this study the applicability of GPS in collection of speed data with high precision in short time is established. It has been observed that SOM in ANN is a very successful clustering tool that can be applied for all kind of urban roads having varying traffic flow. So this tool can be exploited by other developing and developed countries to collect speed data and cluster analysis can be applied to define the speed ranges of LOS categories of their own rather than following some values which are not completely appropriate for the local condition. Hence this study result has got strong application in transportation planning, operation and design. Rather using mid-sized vehicles for data collection purpose this study can be extended to collect data using different types of vehicles and further study can be carried out.

\section{References}

Al-Garni, S.; Abdennour, A. 2008. A Neural Network Based Traffic Flow Evaluation System for Highways, Journal of King Saud University of Engineering Sciences, 20(1): 37-46.

Baumgaertner, W.E. 1996. Level of service: Getting ready for the 21st century, Institute of Transportation Engineers Journal, 66(1): 36-39. 
Bensaid, A.M.; Hall, L.O.; Bezdek, J.C.; Clarke, L.P.; Silbiger, M.L.; Arrington, J.A.; Murtagh, R.F. 1996. Validity guided (re)clustering with applications to image segmentation. IEEE Transactions on Fuzzy Systems, DOI: http://dx.doi.org/10.1109/91.493905, 4(2): 112-123.

Benz, R.J.; Ogden M.A. 1996. Development and Benefits of Computer Aided Travel Time Data Collection. Transportation Research Record: Journal of the Transportation Research Board, DOI: http://dx.doi.org/10.3141/1551-01, 1551/1996: 1-7.

Bhuyan, P.K.; Krishna Rao, K.V. 2010. FCM Clustering Using GPS Data for Defining Level of Service Criteria of Urban Streets. Transport Problems: an International Scientific Journal, 5(4): 105-113.

Brilon, W. 2000. Traffic flow analysis beyond traditional methods, In Proceedings of the Transportation Research Circular E-C018: 4th International Symposium on Highway Capacity, Transportation Research Board, Washington, D.C.: 26-41.

Cameron, R. 1996. G3F7: An expanded LOS gradation system, Institute of Transportation Engineers Journal, 66(1): 40-41.

Cetiner, B.G.; Sari, M.; Borat, O. 2010. A neural network based traffic-flow model, Mathematical and Computational Applications, 15(2): 269-278.

Clark, I. 2008. Level of Service F: Is it really bad as it gets? In Proceedings of the IPENZ Transportation Group Conference, New Plymouth, New Zealand: 198-203.

Florio, L.; Mussone, L. 1995. Neural Network Models for Classification and Forecasting of Freeway Traffic Flow Stability, Transportation System: Theory and application of advanced Technology, 2: 773-784.

Highway Capacity Manual (HCM). 2000. Transportation Research Board, Washington, D.C., USA. 1134p.
Highway Capacity Manual (HCM). 2010. Transportation Research Board, Washington, D.C., USA. 1650p.

Jian-ming, C. 2010. Traffic Prediction Based on Improved Neural Network, Journal of Convergence Information Technology, DOI: http://dx.doi.org/10.4156/jcit.vol5.issue9.8, 5(9): 85-89.

Kita, H.; Fujiwara, E. 1995. Reconsideration on the level of service and a proposed measure. In Proceedings of the $15^{\text {th }}$ Annual Meeting of JSTE, Japan: 25-28.

Kittelson, W.K.; Roess, R.P. 2001. Highway capacity analysis after the highway capacity manual 2000, Transportation Research Record: Journal of the Transportation Research Board, DOI: http://dx.doi.org/10.3141/177602, 1776: 10-16.

Lingras, P. 1995. Classifying highways: Hierarchical grouping versus kohonen neural networks, Journal of Transportation Engineering, ASCE, DOI: http://dx.doi. org/10.1061/(ASCE)0733-947X(1995)121:4(364), 121(4): 364-368.

Maitra, B.; Sikdar, P.K.; Dhingra, S.L. 1999. Modeling congestion on urban roads and assessing level of service, Journal of Transportation Engineering, ASCE, DOI: http:// dx.doi.org/10.1061/(ASCE)0733-947X(1999)125:6(508) 125(6): 508-514.

Murat, S.Y.; Baskan, O. 2006. Modeling vehicle delay at signalized junction: Artificial Neural Network approach, Journal of Scientific and Industrial Research, 65(7): 558-564.

Sharma, A. K.; Sheikh, S.; Pelczer, I.; Levy, G. C. 1994. Classification and clustering using neural networks, Journal of Chemical Information and Computer Sciences, 34(5): 11301139.

Spring, G.S. 1999. Integration of safety and the highway capacity manual. In Proceedings of the 4th International Symposium on Highway Capacity, Transportation Research Board, Washington, D.C., USA. 63-72. 
Turner, S.M.; Eisele, W.L.; Benz, R.J.; Holdener, D.J. 1998.

Travel time data collection handbook, Texas Transportation Institute, The Texas A\&M University System, College Station, Texas. USA. 348p.

Quiroga, C.; Bullock, D. 1998. Travel time studies with global positioning and geographic information systems: An integrated methodology, Transportation Research Part C, DOI: http://dx.doi.org/10.1016/S0968-090X(98)00010-2, 6(1-2): 101-127.

Yang, H.; Qiao, F. 1998. Neural network approach to classification of traffic flow states, Journal of Transportation Engineering, ASCE, DOI: http://dx.doi.org/10.1061/ (ASCE)0733-947X(1998)124:6(521), 124(6): 521-525.
DEFINISANJE KRITERIJUMA ZA UTVREIVANJE NIVOA USLUGA GRADSKE PUTNE MREŽE PRIMENOM SAMOORGANIZOVANE MAPE VEŠTAČKE NEURONSKE MREŽE

\section{Sourava Mohapatra, Prasanta Kumar Bhuyan}

Sažetak: Cilj ovog rada je poboljšanje nivoa usluga za poznata saobraćajna opterećenja gradskih ulica u Indiji. Analiza je sprovedena na osnovu preporuka datih u priručniku Highway Capacity Manual. Preporučeni opseg brzina za različite kategorije nivoa usluga gradskih ulica, odnosi se na razvijene zemlje sa homegenim saobraćajnim tokom. Indija kao zemlja u razvoju, obuhvata heterogeni saobraćajni tok koji se sastoji od vozila sa širokim odstupanjima u pogledu operativnih karakteristika. U tom smislu, kriterijumi za definisanje nivoa usluga se moraju bazirati na saobraćajnim i geometrijskim karakteristikama gradskih ulica. Definisanje nivoa usluge se u osnovi može rešavati klasifikacionim pristupom, a utvrđeno je da je primena klaster analize pogodna tehnika za rešavanje ovog problema. U radu je primenjena samoorganizovana mapa kao tip veštačke neuronske mreže za rešavanje ovog problema. Za potrebe ove studije korišćen je sistem GPS u cilju prikupljanja podataka o brzini vozila, posebno o brzini slobodnog toka i srednjoj brzini vozila tokom i van vršnog perioda. Utvrđeno je da je opseg brzina slobodnog toka za različite klase gradskih ulica, kao i opseg brzina za različite kategorije nivoa usluga niži od navedenog u priručniku Highway Capacity Manual (2000).

Ključne reči: samoorganizovana mapa, veštačke neuronske mreže, nivo usluga, gradske ulice, GPS, klasterovanje. 